\title{
Corrigendum: Exploring, Mapping, and Data Management Integration of Habitable Environments in Astrobiology
}

\begin{abstract}
Marjorie A. Chan ${ }^{1 *}$, Brenda B. Bowen ${ }^{1}$, Frank A. Corsetti ${ }^{2}$, William H. Farrand ${ }^{3}$, Emily S. Law ${ }^{4}$, Horton E. Newsom ${ }^{5}$, Scott M. Perl ${ }^{4}$, John R. Spear ${ }^{6}$ and David R. Thompson ${ }^{4}$

${ }^{1}$ Department of Geology and Geophysics, The University of Utah, Salt Lake City, UT, United States, ${ }^{2}$ Department of Earth Sciences, University of Southern California, Los Angeles, CA, United States, ${ }^{3}$ Space Science Institute, Boulder, CO, United States, ${ }^{4}$ Jet Propulsion Laboratory, California Institute of Technology, Pasadena, CA, United States, ${ }^{5}$ Department Earth and Planetary Sciences, University of New Mexico, Albuquerque, NM, United States, ${ }^{6}$ Department of Civil and Environmental Engineering, Colorado School of Mines, Golden, CO, United States
\end{abstract}

Keywords: astrobiology, habitable environments, authigenic minerals, Mars, cybertechnology, data management

\section{OPEN ACCESS}

Approved by: Frontiers Editorial Office,

Frontiers Media SA, Switzerland

*Correspondence:

Marjorie A. Chan

marjorie.chan@utah.edu

Specialty section:

This article was submitted to Microbiological Chemistry and

Geomicrobiology,

a section of the journal

Frontiers in Microbiology

Received: 23 April 2019

Accepted: 10 May 2019

Published: 29 May 2019

Citation:

Chan MA, Bowen BB, Corsetti FA,

Farrand WH, Law ES, Newsom HE,

Perl SM, Spear JR and Thompson DR

(2019) Corrigendum: Exploring,

Mapping, and Data Management Integration of Habitable Environments in Astrobiology.

Front. Microbiol. 10:1190 doi: 10.3389/fmicb.2019.01190

\section{A Corrigendum on}

Exploring, Mapping, and Data Management Integration of Habitable Environments in Astrobiology

by Chan, M. A., Bowen, B. B., Corsetti, F. A., Farrand, W. H., Law, E. S., Newsom, H. E., et al. (2019). Front. Microbiol. 10:147. doi: 10.3389/fmicb.2019.00147

"Scott M. Perl" was not included as an author in the published article and has now been added. All authors listed have made a substantial, direct and intellectual contribution to the work, and approved it for publication.

Additionally, due to the addition of the author Scott M. Perl, a correction has been made to the Acknowledgments section:

"A portion of this research took place at the Jet Propulsion Laboratory, California Institute of Technology, under a contract with the National Aeronautics and Space Administration. General ideas presented here developed out of various NASA and NSF grants to the authors, along with partial support from the NASA Astrobiology Institute (project: Rock Powered Life) to JS, NSF Coupled Natural Human Systems (Award \#1617473) to BB, and NSF National Robotics Initiative (Award \#IIS-1526667) for DT. We thank the reviewers for input that improved this manuscript."

The authors apologize for this error and state that this does not change the scientific conclusions of the article in any way. The original article has been updated.

Copyright (c) 2019 Chan, Bowen, Corsetti, Farrand, Law, Newsom, Perl, Spear and Thompson. This is an open-access article distributed under the terms of the Creative Commons Attribution License (CC BY). The use, distribution or reproduction in other forums is permitted, provided the original author(s) and the copyright owner $(s)$ are credited and that the original publication in this journal is cited, in accordance with accepted academic practice. No use, distribution or reproduction is permitted which does not comply with these terms. 